\title{
Review of the Exhibition Oppression and Overcoming: Social Movements in Post-War Taiwan, National Museum of Taiwan History, 28 May 2019-17 May 2020
}

\author{
Susan Shih Chang \\ Department of Communications and New Media, \\ National University of Singapore, Singapore \\ chang.shih@u.nus.edu \\ Jeremy Huai-Che Chiang \\ Department of Politics and International Studies, University of Cambridge, \\ Cambridge, United Kingdom \\ hcc63@cam.ac.uk
}

\begin{abstract}
This review article looks at "Oppression and Overcoming: Social Movements in PostWar Taiwan" (2019.5.28-2020.5.17), an exhibition at the National Museum of Taiwan History (NTHM) through approaches of museum studies and social movement studies, and aims to understand its implication for doing Taiwan Studies. This review concludes that "Oppression and Overcoming" is significant as a novel museological practice by being part of a continuation of social movements, which transformed the museum to a space for civil participation and dialogue. This allows the exhibition to become a window for both citizens and foreigners to understand and realize Taiwan's vibrant democracy and civil society. In addition, this review suggests that future
\end{abstract}


exhibitions on social movements could demonstrate the possibility to position Taiwan in a global context to better connect with other countries in the Asian region.

\section{Keywords}

Taiwan - museum - exhibition - social movement

Upon reaching the fourth floor of the museum building, the glass elevator door opens and there is, facing the visitors, a black-and-white photo of a girl holding an amplifier. Various banners of protest as well as a warning sign from the police are scattered behind her (Figure 1). This is not something typical in a history museum. Oppression and Overcoming: Social Movements in Post-War Taiwan (28 May 2019-17 May 2020) is one of the latest exhibitions at the National Museum of Taiwan History ( $\mathrm{NMTH}$ ) that looks at contemporary issues in Taiwan's society. ${ }^{1}$ This exhibition is unique because it is curated on the basis

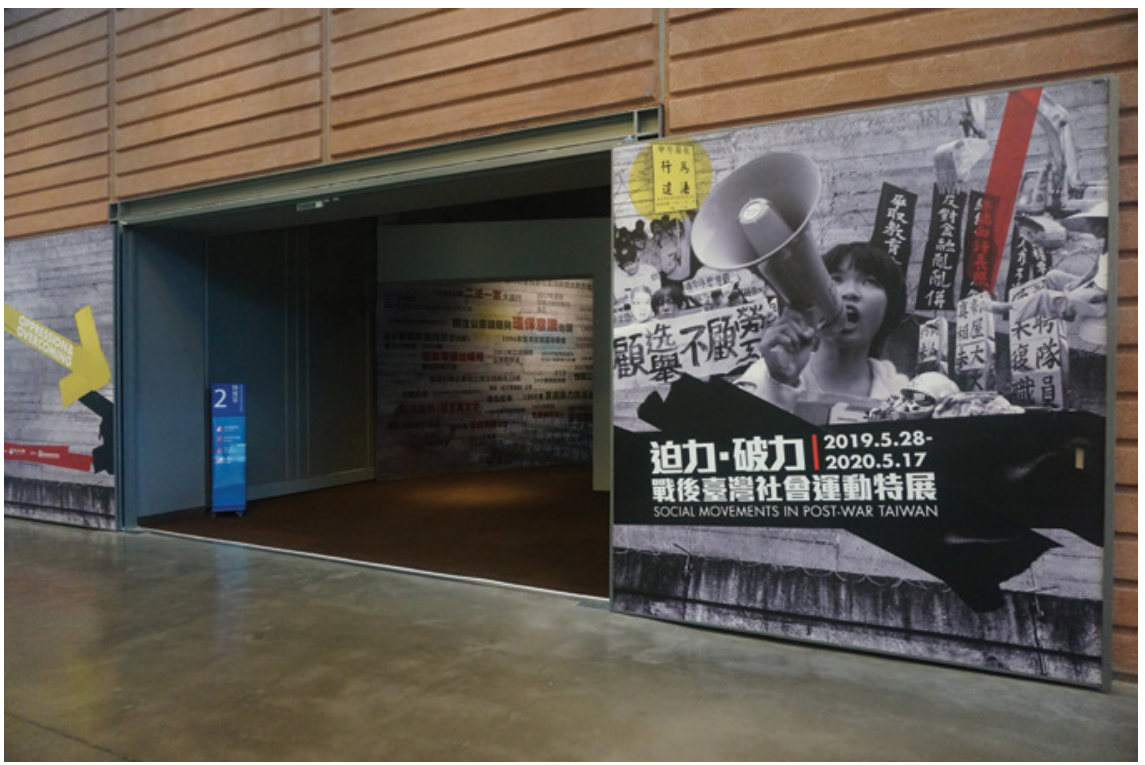

FIGURE 1 The entrance to the exhibition hall.

Note: All photographs in this article were taken by the authors.

1 For this paper, several visits were made during May to November 2019. An unofficial interview was given with members of the curatorial team to understand their agenda and inspiration for putting up this exhibition. 
of long-term field and archival research by the museum's curatorial team, in collaboration with academia, several non-governmental organisations, and private individuals. The aim of the exhibition is to respond to societal needs of collective history and personal memories of often marginalised communities.

Museums are one of the most trusted institutions in our society, but they are more than that. Museums are 'agents of social inclusion' (Sandell, 1998: 401), 'engines of social transformation' (Bennett, 2006: 57), and they 'actively seek to confront prejudice, provoking dialogue and debate and fostering understanding' (Gourievidis, 2014: 10). Museums' voices carry weight when they speak, and because they are not separated from their social and historical context and carry responsibility to the betterment of societies, museums are not neutral (International Council of Museums, 2019). In this sense, Oppression and Overcoming is significant as a crucial and meaningful museological practice by being part of a continuation of social movements. Through exhibitions and outreach programmes, the museum plays the role in transferring vertical and intergenerational knowledge, which differentiates Taiwan from other nation states within the Asian region. Through displaying social struggles and civil disobedience the exhibition has strong implications for civil education. To demonstrate the prominence of this exhibition, this review article is divided into three parts. First, it gives an overview description of Oppression and Overcoming and how it aligns with the missions of the NMTH. Second, it will critique and comment on its implications for museum studies and social movement studies, such as the politics of exhibiting social movement history, as well as how this exhibition transformed the museum in to a space for civil participation. Third, it discusses how this exhibition reflects Taiwan's vibrant democracy and civil society, and how more could be done to better position Taiwan in a global context.

\section{The Museum and the Exhibition}

After nearly two decades of planning, in 2011 the public welcomed the NMTH, the first national museum dedicated to Taiwan's culture and history, with its mission statement:

The Museum's main objectives are the collection, categorization, preservation, research, exhibition, education and promotion of artefacts that are related to Taiwan's history and culture ... to become the leading research centre for Taiwanese history. (National Museum of Taiwan History, n. d.) 
The museum's location at the Annan District of Tainan City is a symbol for this statement, as Tainan is not only one of the oldest (cultural) cities of the island, but it is also where initial contacts with outsiders were made through the Taijiang Inner Seas in the 180os. The primary goal of the museum's establishment was to present the rich and diverse facets of Taiwanese history through interdisciplinary approaches including archaeology, ethnology, folk studies, and museology (National Museum of Taiwan History, n. d.), which were previously dominated by a Chinese-centred narrative. Moreover, the museum aims to unveil the interaction between different ethnic and social groups of Taiwan through various historical topics and contemporary issues. Up to now, the museum has curated exhibitions that cover a range of topics, such as immigration, baseball, and the role of women in Taiwan's history.

The exhibition Oppression and Overcoming: Social Movements in Post-War Taiwan aligns with the grand mission of NMTH, allowing people within social movements, who are used to being misrepresented, a platform to tell their stories, and prompting visitors to think about how civil disobedience and fighting for room for counter-narratives have always been part of national history. The exhibition is divided into three over-arching themes: 'Warm-Up', 'Starting Off', and 'A Vibrant Society', with each using different events and incidents to showcase different stages of a social movement. Featuring an abundance of cases instead of focusing on one particular movement, Oppression and Overcoming allowed the museum to examine the role of objects, technology, communities, and personal stories in moments of social change.

'Warm-Up' shows visitors how a social movement is formed and how groups mobilise and communicate with each other. Using student-led movements in the past and present as examples, the exhibition shows that modern-day protests are mobilised through new social media, which differs from the traditional tightly organised forms of social movements. The exhibition displayed a booklet that provided guidelines for 'non-violent action', published by lawyer Jian Pengjian in 1983. The booklet provides first-aid instructions and help-kit information for protesters. Alongside the booklet is a handbook on self-defence published in 2015, provided to the museum by the Taiwan Association for $\mathrm{Hu}-$ man Rights. The handbook includes information and particulars for protesters should they find themselves needing help before, during, and after a protest to protect their own rights. Other objects on display include flyers, telephone recordings, and radio broadcast tapes that overseas Taiwanese relied on to stay connected with the situation in the country (Figure 2). Since the Internet plays a crucial role in today's demonstrations, a monitor screen is placed in the exhibition to show how people interact on Facebook pages to share information, ask for resources, argue, and debate (Figure 3). 


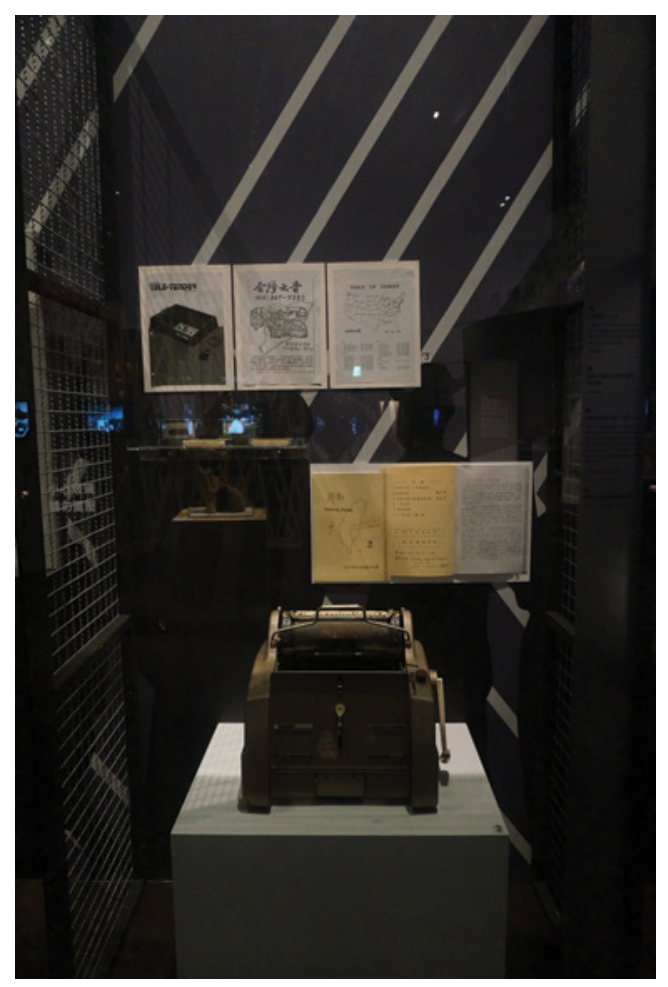

FIGURE 2

Objects that show overseas support for protests for democracy. From top to bottom, a copy of 'Voice of Taiwan', founded in 1977 in New York; a copy of the 'Newsletter of Taiwanese Association in Belgium' in 1971; the printer for of the 'Newsletter of Taiwanese Association in Belgium'. In the background: a recording tape for 'Voice of Taiwan'.

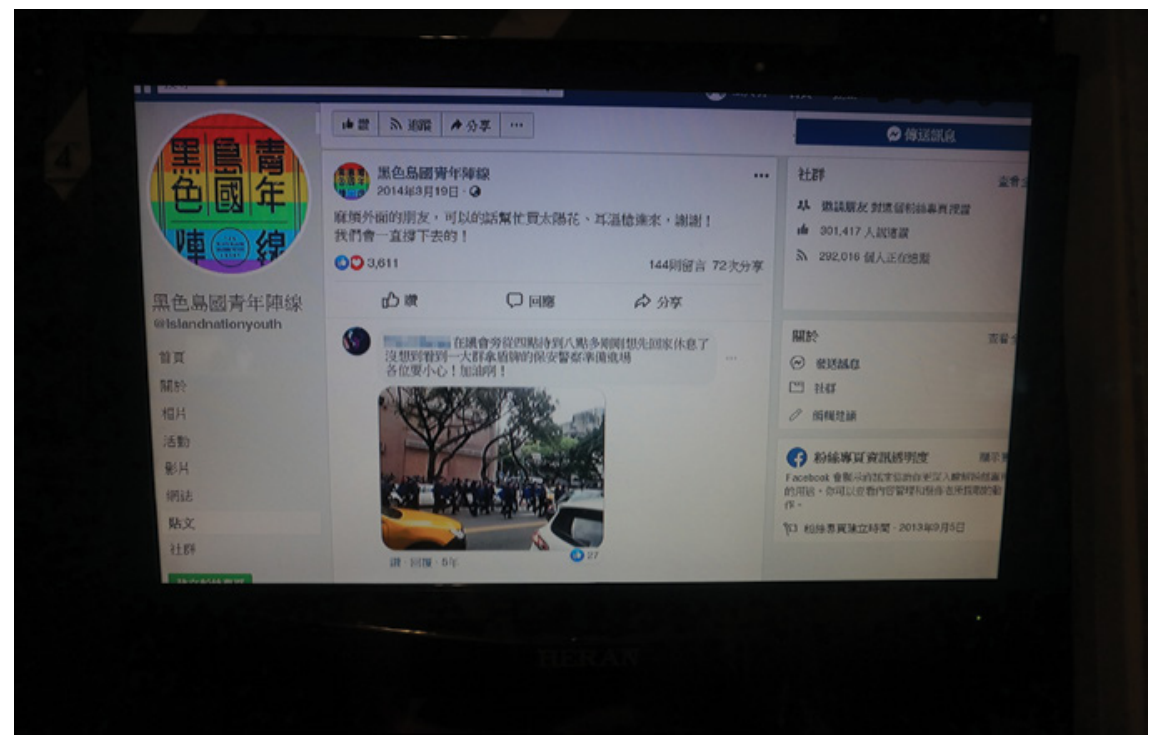

FIGURE 3 Facebook page of The Black Island Nation Youth Front during the Sunflower Movement. 


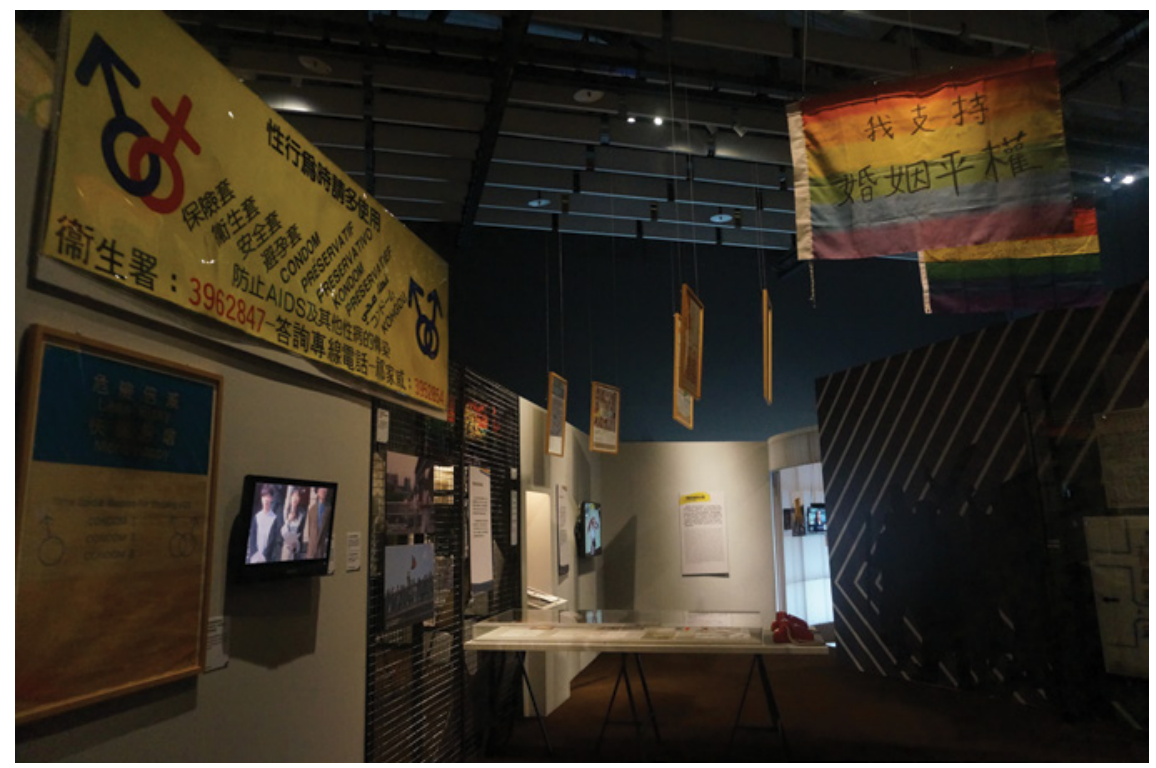

FIGURE 4 Inside the exhibition hall, in the "Starting Off" section.

'Starting Off' documents real-time action of civil disobedience and the stories of the protesters. Turning right, visitors will immediately notice a rainbow flag with the words 'I support marriage equality' hanging above (Figure 4). The highlight of this section is a TV screen showing an interview with the mother of Yeh Yong Zhi, a 14-year-old who was bullied for his sexuality, which eventually led to his tragic death. Yeh was only in ninth grade when he was found dead after going to the restroom during class time in the morning of 20 April 200o. Yeh had been bullied often for his sexuality and although a high court concluded that the tragedy happened 'because he slipped', much of the evidence does not add up, and his death prompted the government to enact the Gender Equity Education Act (性別平等教育法) in 2004. In the interview shown in the museum, Yeh's mother shares how her son's sexuality was seen as a 'sickness' by the school teachers and administrators, and urges the government to bring in sex education in early school years. The most touching moment is her description of how she eventually became a force for those afraid to face their sexuality due to societal pressure. 'I lost my son, now I have to save other kids like him. If I can rescue them by standing out, I am willing to,' Yeh's mother says, tearing up. Two years after Yeh's passing, Taiwan passed the Gender Equality Education Act, and in 2019 the country became the first in Asia to legalise same-sex marriages. 'My kids, be brave. God created you so that you can have rights as others.' This revolutionary moment is made even more powerful with a display of banners, leaflets, and condoms that had been handed 


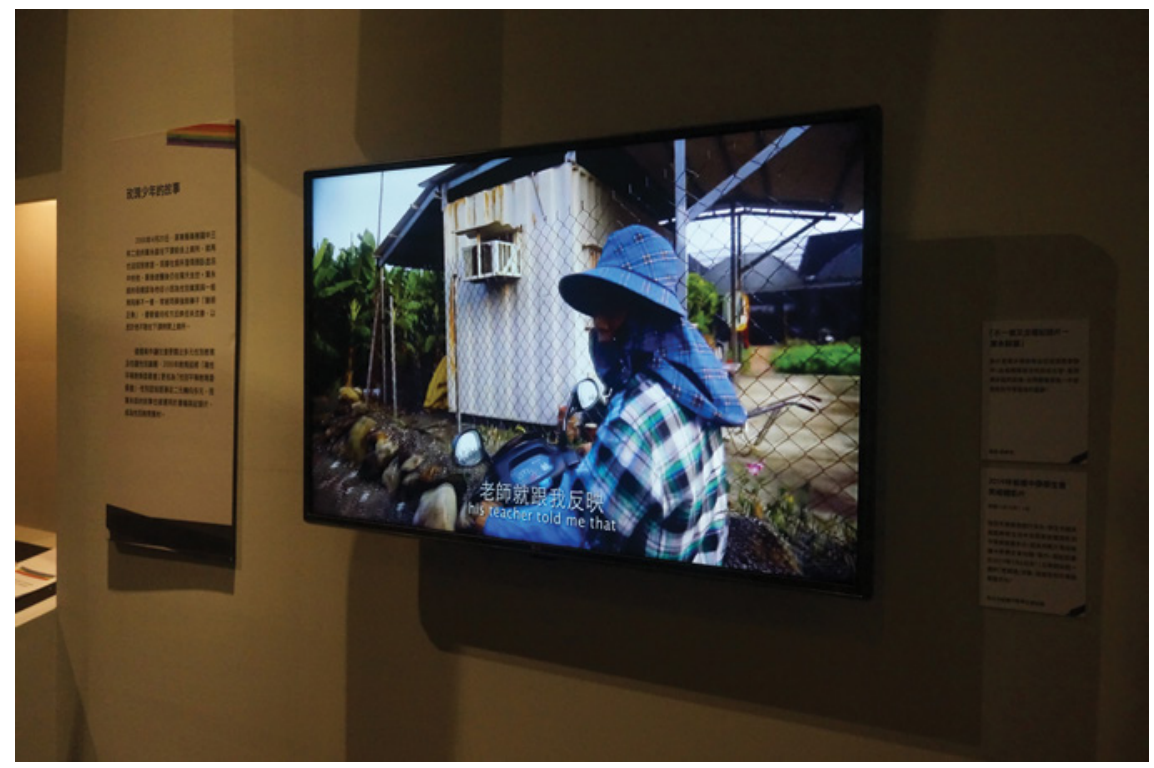

FIGURE 5 Installation of interview with Yeh Yong Zhi's mother.

out during various protests in previous decades to battle misunderstanding of homosexuality. 'Be yourself. Don't be afraid.' These strong words and the firm voice of Yeh's mother echo in the exhibition hall and will perhaps echo in visitors' hearts (Figure 5).

Turning left, visitors see a recorded interview with a young indigenous student. The 'Return Our Lands' movement which started in the 1980s represents a new phase of Taiwanese history in recognising indigenous rights. In addition to fighting for the right to live and protect their culture, they also experienced racial discrimination and unfair treatment at the hands of the majority Han Chinese. Particularly significant objects on display include a copy of Gao-Shan-Qing Magazine (高山青), which reads, 'Yes we killed Wu Feng (吳鳳), because he is an exploiter’2 (Figure 6), and a statement, 'Fully Delete Wu Feng's Myth and Give Us Justice,' ${ }^{3}$ by the Taiwan Indigenous Group, representing the self-awareness of the youth of indigenous communities in seeking to diminish the myth of Wu Feng (Figure 7). The exhibition shows that for almost a century Wu Feng was known and remembered as a selfless, compassionate hero, and branded as a Han Chinese who could 'civilize the savages' (Cheung, 2017). 'Wu's downfall began in 1980, when anthropologist Chen Chi-nan (陳其南) wrote an article for the Minsheng Daily (民生報) titled

2 The authors' translation.

3 The authors' translation. 




FIGURE 6 Display object includes a copy of the 'Gao-Shan-Qing Magazine’ vol. 2.

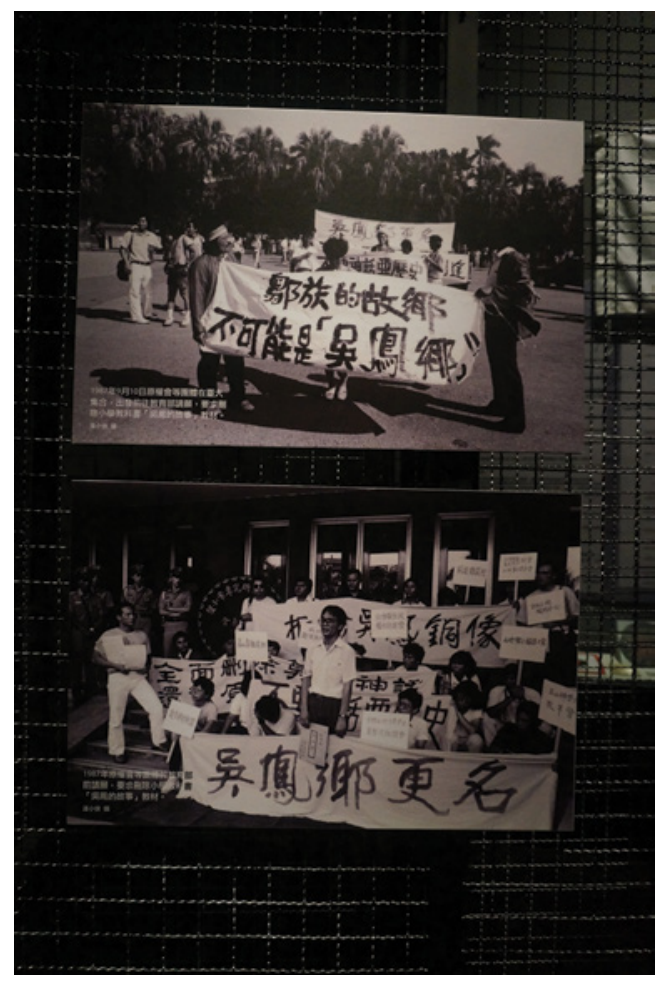

FIGURE 7

Photos of two protests in 1987 by the Alliance of Taiwan Aborigines requesting the Ministry of Education to delete the story of Wu Feng from school materials. 
“A Fabricated Legend: Wu Feng (一個捏造的神話：吳鳳)”' (Cheung, 2017). The indigenous rights movement soon escalated, along with other protests which led to the Ministry of Education eventually deleting the story of Wu Feng from school materials in 1989. In the same year, Wu Feng Village was also renamed Ali Village to acknowledge the home town of several indigenous groups. The 'Anti-invasion, Strive for Survival and Return my Land' petition letter to the Executive Yuan in 1993 placed at the end of this section is evidence that while a certain degree of progress has been made, the fight is not yet over.

Continuing along, visitors reach a small section that documents perhaps the most known protest of this generation, the Sunflower Movement in 2014, in which students engaged in mass demonstrations and acts of civil disobedience by storming into Taiwan's legislature to prevent the passing of the Cross-Strait Service Trade Agreement. This incident gave rise to other student movements ${ }^{4}$ such as the Anti-Black Box Curriculum Movement in 2015, led by Taiwanese high school students to stand against changes in guidelines on high school history curriculums (Figure 8). Students questioned the changes in the content

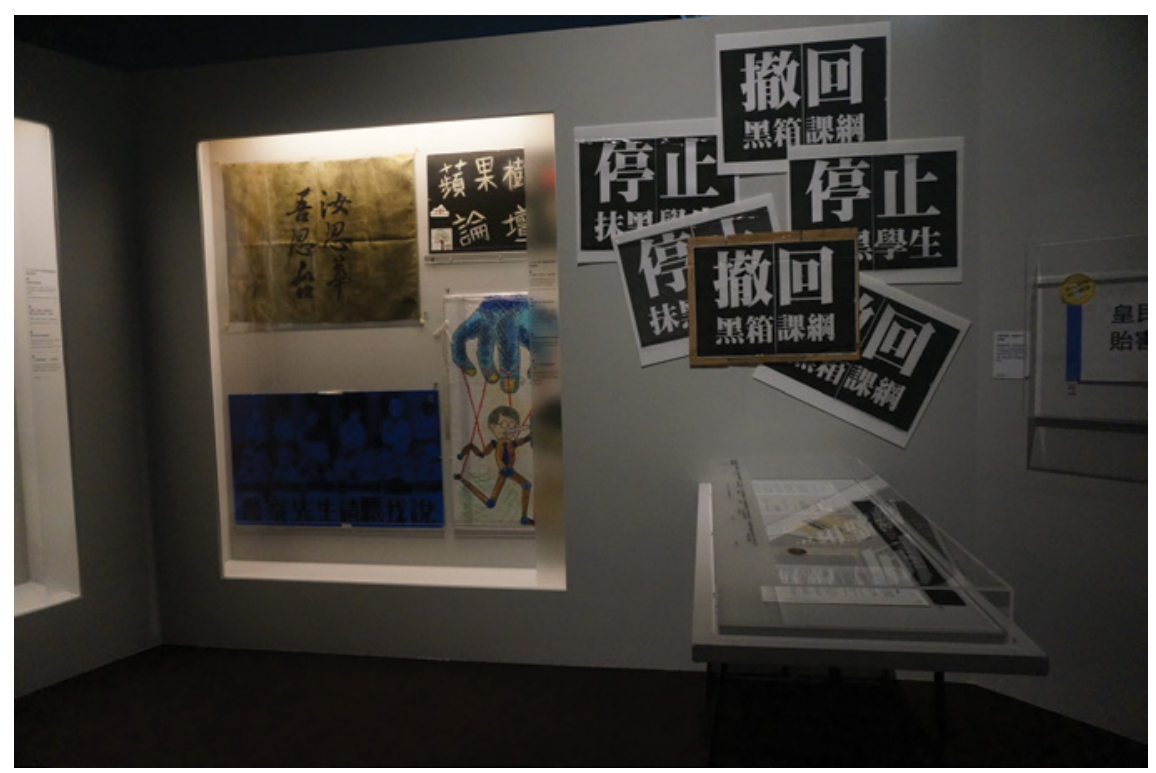

FIGURE 8 Protest objects of the Anti-Black Box Curriculum Movement in 2015.

4 Student mobilisation was an important part of Taiwan's social movements that have contributed to the island's democratisation since the 1980s. For example, the Wild Lily Student Movement of 1990 helped to dissolve the National Assembly and inspired the Wild Strawberry Movement in 2008 (Swarthmore College, n. d.; Wright, 1999). 
of the history curriculum as an aim to re-Sinicise Taiwan's history in line with the Kuomintang's (кмт) ideology. Recorded interviews with youth participants allow visitors to understand the reasons behind organising social movements and participating in demonstrations, as well as how these events changed the trajectories of their lives. This section of the exhibition also features other protests and movements includes the very recent strikes by the flight attendants of China Airlines and EvA Air (Figure 9). This brings attention to another societal facet-labour rights issues in Taiwan - and shows that the significant progress made was due to brave people making their voices heard through various means.

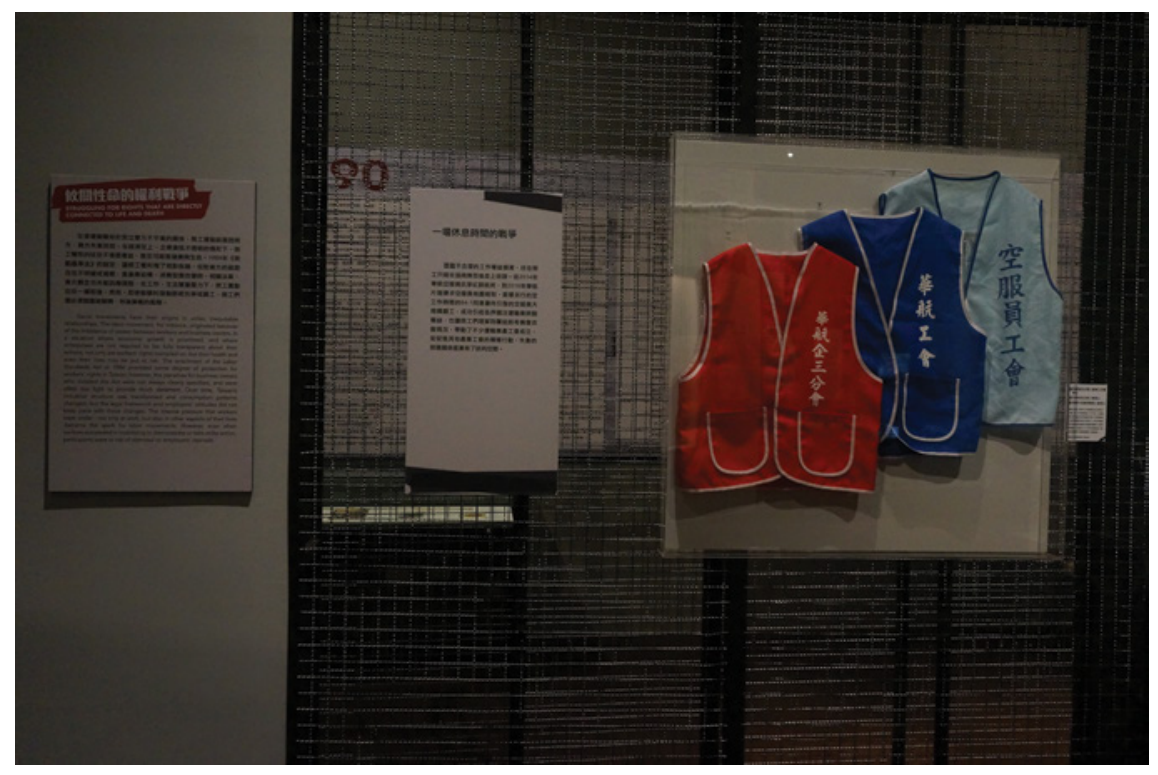

FIgURE 9 Uniform of China Air Unions and the Taoyuan Flight Attendants Union.

The exhibition ends with 'A Vibrant Society', which looks at the impact of social movements. Visitors are invited to ponder on Taiwan's democratic and multicultural society and how that is made possible with the participation of every individual and organisation. The various identities of belonging performed in the social movements reflect Taiwan's vibrant society and complex position in the current global context. The exhibition ends with a fitting climax - a piece of the Lennon Wall, originally erected at the Gongguan underpass in Taipei City from 2 to 31 August 2019 in support of the Hong Kong demonstration (Figure 10). This section was recently added in collaboration 


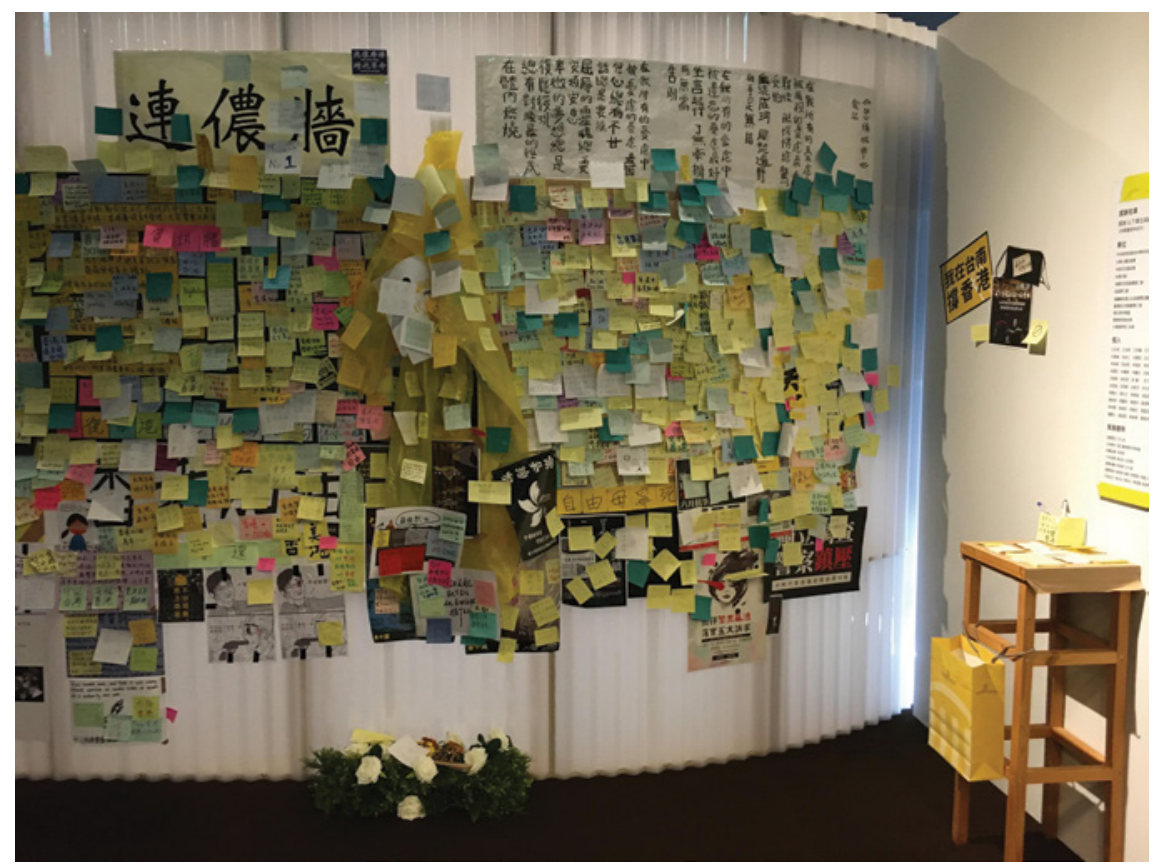

FIGURE 10 Post-it notes and other documents from parts of the Lennon Wall, originally erected at the Gongguan underpass.

with Hong Kong Outlanders, the organiser of the Lennon Wall 5 installation, as both parties see the importance of adding this piece of the wall to the collection of Taiwan's modern civil society history.

Several themes that run though the exhibition can be identified. Fighting stereotypes and the damage they cause are continuous actions that make a stand against dominant discourses. Fighting for rights and the right to dissent show that society has the power to limit authoritarian populist agendas in a democratic society. Especially in connection to those who were fighting for rights and rights principles at during the year in which this exhibition was held, it demonstrates the novel curation concept and method of how the museum is not simply a place where history is remembered, but also where contemporary events that continue to shape today's society are discussed.

5 Originally referring to a John Lennon-inspired graffiti wall in Prague, Czech Republic. A similar installation appeared during the 2014 democracy protests in Hong Kong, with people covering the wall with colourful post-it notes. The same wall was created during the 2019 Hong Kong anti-extradition bill protest, with similar walls created in cities such as Taipei, Tokyo, Sydney, and Toronto. 
Why is it crucial to exhibit social movements today? Taiwan's modern history of social movements can be traced back to the Japanese occupation. They impacted, and continue to impact, Taiwan's civil society and helped form the democratic society that we have today. Inspired by the Disobedient Objects exhibition held at the Victoria \& Albert Museum in London from July 2014 to February $2015,{ }^{6}$ and having long believed that museums should represent minority and marginalised voices in society, ${ }^{7}$ the Oppression and Overcoming exhibition examines the role of objects in movements for social change but places emphasis on the stories of the people who participated in political activism, who are witnesses to inequality, oppression, and political injustice, and who take on roles to become guardians of democracy and drivers of social change. The curators mentioned that for the V\&A exhibition, a separate 'response room' was set up to showcase instant responses to crises currently happening around the world. For example, a yellow umbrella symbolising the Yellow Umbrella Revolution was exhibited to draw visitors' attention to the Occupy Central with Love and Peace event in Hong Kong in 2014. This pushed the NMTH curatorial team to think about other creative and responsive ways the museum could better engage with visitors on the themes of current social movements as well as other social issues in Taiwan and around the world. For the museum, to include materials from the 2019 Hong Kong Anti-Extradition Bill protest while the demonstration was still being carried out represented a form of instant and direct response to social issues in Taiwan and around the world.

This being the museum's second exhibition on social movements, Oppression and Overcoming has taken a great leap in not only introducing the public to the nature of civil disobedience but also demonstrating how these 'eventful protests' (della Porta, 2014: 17) are processes that lead to transformative, history-making moments. Sidney Tarrow identifies social movements as the collective and sustained challenges mounted by a group of people with common purpose and mutual solidarity (1994: $3-4)$. Social movements therefore offer social scientists a vantage point from which to understand how 'individual efforts accumulate into a collective force capable of generating social changes' (Ho, 2019: 211). Taiwan's civil resistance history tells us that the democratic system and freedom we have now are fragile and need to be defended

6 Interview with the NMTH curatorial team.

7 Interview with the NMTH curatorial team. 
continuously. The stories of various actors in the exhibition not only touch hearts by showing that they fought for what they believe in to make a better living environment for minority communities in that era, but also envisioned a society for future generations. The exhibition both highlights the importance of social movements in shaping a robust civil society and demonstrates how far Taiwan has come; and thus carries a message that democracy, freedom, and equality require continuous defence and safeguarding. The opportunity to shatter the social and political status quo and break down gender and racial injustice occurs only when citizens are willing to directly challenge the existing power structures that underpin them. In addition, the exhibition transformed the museum into a space for continuous civil participation. Demonstrations on labour rights, environment, education, and gender issues, for example, show how different movements were mobilised in relation to the social context of the time. By using different events to represent different stages of a social movement trajectory, the exhibition also presents how actors demonstrate the ability to learn from mistakes and experiences, as well as adopt new technologies.

Another contribution that the exhibition made with regard to social movement studies is how it examines the lives of the protesters and illustrates how a social movement can change the trajectories of individual lives, as well as how they continue to embody the ideas of social change in different walks of life. Visitors are given the chance to see interviews with protesters and activists, to understand the reasons why social movements are organised and how protests are held. This approach, while often applied in museum spaces, shows the role of individual actors in social movements, something that is often overlooked in social movement studies, which tend to focus political contexts and social structures (McAdam, Tarrow \& Tilly, 2001). According to Ho (2019), participation in social movements is often linked to certain political opportunities. Scholars of social movement studies also look at shift mechanisms and filter mechanisms within this structure of political opportunities. While scholars do take a biographical approach in understanding the lives of protesters, their interests lie mostly in understanding the roles that class, gender, and race play with regard to the position and resources the actor holds (Goldstone \& McAdam, 2001). In addition to departing from the classical research agenda (Ho, 2019) of social movements, NMTH's exhibition exemplifies how dissent is performed and dramatised in public, and how it continues in the form of display. Visitors who are unfamiliar or uncomfortable with certain issues are invited to enter in to a dialogue as they walk through the exhibition. In addition, the process and production of the exhibition is itself a kind of social movement and form of dissent. First, the curatorial team mentioned that not every 
political group or individual agreed with their narratives and perspectives. The will to continue provoking historical debates and offering a platform for minority groups is to take a political stand in itself. Second, this exhibition allows for a rethinking of the museum's relationship with society. Museums today, despite changing definitions, are still considered cultural institutions that safeguard a nation's 'past'. The concept of 'collecting the present' not only challenges this perception but also poses a difficult task for museum practitioners. If we are to collect the present, what are we to collect? Therefore, we argue that to include the Lennon Wall originally placed in Taipei City demonstrates how museum exhibitions are not static projects but ongoing processes that create a dialogue with contemporary society, for instance through exhibition changes and contemporary collections. This is also one of the highlights of this exhibition, since it allowed the museum curators to use the concepts of social movement and change to rethink their own roles and positions within the institution. Whether NMTH can continue to provide such counter-discourses to state and dominant narratives remains to be seen, but it is certainly something that is worth looking into in the future.

\section{Going Global and Implications for Taiwan Studies}

Based on the above analysis, Oppression and Overcoming presents rich material for the study of Taiwan's social movements and their significance to democratic change and cultural transformation in the post-authoritarian era. The museum and the exhibition are valuable resources for Taiwan studies scholars, especially those in the fields of anthropology, sociology, and political science. However, while the locally orientated narrative of this exhibition could provoke emotional responses in local visitors, we argue that more could be done to enhance the meaning of this exhibition. As Williams argues, 'Remaining relevant is key to a museum's meaning and its mission. However, this requires the museum exhibit objects that are meaningful for their local, national and global constituents' (2017:68). Addressing global issues forces museums to make decisions when engaging in controversial and political dialogues. 'Museums perform their most fruitful public service by providing an educational experience in the broadest sense: by fostering the ability to live productively in a pluralistic society and to contribute to the resolution of the challenges we face as global citizens' (American Association of Museums, 1992). How museums can find global relevance may offer ideas to similar questions as well as intellectual challenges that people have been attempting to address within Taiwan studies. 
While Taiwan studies has been gaining steam domestically and (to a lesser degree) abroad, and not yet 'in decline or marginalized' (Sullivan, 2011: 718), the necessity to find global relevance seems to have been permanent as a result of Taiwan's international status, constantly being pressured to compare and situate itself within larger disciplinary interests to advance its reach. Ho, Huang, and Juan point out that single-case studies are still the most popular research design in social movement studies, while most comparative cases have taken place between Taiwan and South Korea (2018: 125-126). Comparing Hong Kong to Taiwan has also been gaining traction as a result of similar political pressures put forward by China (Ho, 2019). As much as associating Taiwan with South Korea (both underwent Japanese colonialism) and Hong Kong (both discontent towards China's heavy handling) might be obvious and promising choices, Taiwan social movements and its related political, social, and economic processes can and should also be compared beyond these two options. Other comparatively unexplored options including the Philippines, Malaysia, and Indonesia could spark new research outcomes, especially in exploring how different countries experienced anti-communist authoritarian regimes and civil discontent during the Cold War.

That being said, to take this further, while comparative research offers new viewpoints, Taiwan studies can do more than simply being comparative as a methodological option. With the risk of sounding cliché, Taiwan is and has always been global in nature. As Shu-mei Shih rightly points out, Taiwan is 'a crucial site' of 'global processes and a co-producer of those processes' (Shih, Harrison, Chiu \& Berry, 2018: 213). Through situating itself as both a transnational node and agent, Taiwan studies may be able to expand its audiences beyond scholars interested in traditional Cold War and China/cross-Strait frameworks. For example, how do we situate Taiwan's social movements, intellectuals, and activists during the Japanese colonial period and under кмт's authoritarian regime within larger transnational/global networks such as in Pankaj Mishra's From the Ruins of Empire: The Intellectuals Who Remade Asia (2013), an intellectual attempt which connected various Asian intellectual thinkers in times of Western dominance?

For example, what historical importance would individual figures such as Lin Hsien-tang and Su Beng possess in the Japanese empire and the wider region? Both of them ventured beyond Taiwan in pursuit of the island's future, the former leading the Petition Movement for the Establishment of a Taiwanese Parliament during the Japanese colonial period, the latter first spending time in China working for the Communists and later in Japan for the Taiwan independence movement. Lin even embarked on a year-long trip across the world in 1927, jotting down insightful social commentary during his time in 
Europe, the United States, and beyond. Their trajectories came across nonTaiwanese peoples and events, and their deeds would certainly have been known by other Asian contemporaries, even if not at the level of figures Mishra describes such as Jamal al-Din al-Afghani, Rabindranath Tagore, and Liang Qichao. This begs the question: How should we understand Lin and Su's historical significance beyond Taiwan's own history? And what would their lived experiences look like if we compared them with other anti-colonial activists in the Korean peninsula and resistance figures in occupied Manchuria? Or even other contemporaries in colonial Southeast Asia under British, French, American, and Dutch rule? These intellectual exercises could be fruitful for our understanding of Taiwan's history, and would also be a strong premise for an educational programme aimed at helping Taiwanese people reimagine their historical connections with the world.

What does the above-mentioned issues of 'comparing' and 'globaling' have to do with this exhibition at NмTH? They can be seen as indicative of areas where Oppression and Overcoming may be relatively insufficient. Peoples and ideas in Taiwan's social movements travelled across borders, and were well attuned to events in China, Japan, United States, and beyond. Social movements in Taiwan often developed in parallel, or learned from or influenced movements in other countries. For example, during the 1980 s the indigenous movement was active in Asia. In the Philippines the Cordillera People's Alliance was formed in 1984 and this was followed by subsequent mobilisation throughout Asia. Several indigenous communities in Asia such as the Ainu of Japan, the Aboriginal peoples of Taiwan, and those from Thailand, Malaysia, and Indonesia all joined in 1992 to form the Asian Indigenous People's Pact (Anti-Slavery International \& International Work Group for Indigenous Affairs, 1997: 8). Taiwan's Sunflower Movement and Hong Kong's Umbrella Movement echoed each other in 2014, subsequently enhancing the already growing solidarity of China-wary young social activists in both places. In addition, in April 2016 Sunflower Movement leader Lin Fei-fan joined forces with Joshua Wong of Hong Kong and many other young pro-democracy social activists in East Asia to found the Network of Young Democratic Asians (NOYDA), a transnational organisation which included members from Taiwan, Hong Kong, Thailand, Myanmar, Vietnam, the Philippines, Japan, and Mongolia. NOYDA illustrated that despite variances in contexts across countries, East Asian youth activists still deemed mutual interests solid and necessary enough to organise transnationally. While exhibiting and reflecting on Taiwan social movements alone is detailed, focused, and caters to local visitors, connecting developments in Taiwan to a global context can be beneficial not only as an academic project, but also as an educational one. When Taiwanese feel marginalised in the world, or 
that they somehow must 're-join' it, narratives of social movements and global connections can remind them that they have always been part of the world, and in some regards have never stopped exerting influence. Consequently, Taiwan's social movements have the potential to be exhibited as historical events both for local consumption and also serve as a microcosm for the regional and global community. Building on the current outcomes of Oppression and Overcoming, future exhibitions could strive to show how social movements should be seen as Taiwan's linkages with other countries, not just a product of these transnational interactions, as the island's civil discontent has truly shaped and been shaped by global trends.

\section{$4 \quad$ Conclusion}

The NMTH's Oppression and Overcoming exhibition demonstrates social movement as Taiwan's strength as a democratic and vibrant society. It also shows how a museum can take responsibility in collecting a nation's 'present' as well as narrating history that aligns with universal values. Future exhibitions on social movements building on the path of this one could benefit by showing how Taiwan has always been global, such as looking towards Northeast Asia and the West to discover international connections for social movement experiences and interrogating possible transnational advocacy networks that extended into South and Southeast Asia. This will not only demonstrate NMTH's strength in narrating a Taiwan history that positions Taiwan in a global context. More importantly, it will assist in consolidating Taiwan's multicultural identity beyond its Chinese, Japanese, and Western-influence legacies, and help problematise and reconceptualise what it means to be Taiwanese.

\section{Susan Shih Chang}

is currently a PhD candidate with the Cultural Studies in Asia Program at the National University of Singapore. Her doctoral research revolves around the imaginaries of national discourse in relation to (im)migration and diaspora communities. Her research interests include cultural sociology, museum studies, and cultural policy studies, with a focus on Taiwan and Singapore.

\section{Jeremy Huai-Che Chiang}

is currently an MPhil candidate at the Department of Politics and International Studies at the University of Cambridge. His broad research interests include Chinese foreign policy, Taiwan/cross-Strait relations and the intersection between history, politics, and economics in Southeast Asia. 


\section{References}

American Association of Museums (1992) Excellence and Equality: Education and the Public Dimension of Museums, Washington, DC: American Association of Museums. Anti-Slavery International and International Work Group for Indigenous Affairs (1997) Enslaved Peoples in the 199os, Copenhagen: Eks-Skolens Trykkeri aps. Retrieved 10 February 2020 from https://www.iwgia.org/images/publications/o142_ENSLAVED _PEOPLES_IN_THE_9o.pdf.

Bennett, Tony (2006) 'Exhibition, difference, and the logic of culture', in Ivan Karp, Corinne A. Kratz, Lynn Szwaja, and Tomas Ybarra-Frausto (eds), Museum Frictions: Public Cultures/Global Transformations, Durham, NC: Duke University Press, 46-69. Cheung, Han (2017) 'Taiwan in time: The drastic downfall of Wu Feng', Taipei Times, 10 September. Retrieved 26 December 2019 from: http://www.taipeitimes.com/News/ feat/archives/2017/09/10/2003678150/2.

Goldstone, Jack and McAdam, Doug (2001) 'Contention in demographic and lifecourse context', in R. R. Aminzade, J. A. Goldstone, D. McAdam, E. J. Perry, W. H. Sewell Jr., S. Tarrow, and C. Tilly (eds), Silence and Voice in the Study of Contentious Politics, Cambridge: Cambridge University Press, 195-221.

Gourievidis, Laurance (2014) 'Representing migration in museums: History, diversity and the politics of memory', in Laurance Gourievidis (ed), Museums and Migration: History, Memory and Politics, London: Routledge, 1-24.

Ho, Ming-Sho (2019) Challenging Beijing's Mandate of Heaven: Taiwan's Sunflower Movement and Hong Kong's Umbrella Movement, Philadelphia, PA: Temple University Press.

Ho, Ming-Sho; Huang, Chun-hao; and Juan, Chun-ta (2018) 'The institutionalisation of social movement study in Taiwan', International Journal of Taiwan Studies 1(1): 115-140.

International Council of Museums (2019) 'Museums do not need to be neutral, they need to be independent', 6 January. Retrieved 26 December 2019 from https:// icom.museum/en/news/museums-do-not-need-to-be-neutral-they-need-to-be -independent/.

McAdam, Doug; Tarrow, Sidney; and Tilly, Charles (2001) Dynamics of Contention, New York: Cambridge University Press.

Mishra, Pankaj (2013) From the Ruins of Empire: The Revolt Against the West and the Remaking of Asia, London: Picador.

National Museum of Taiwan History (no date) 'Vision and mission'. Retrieved 10 February 2020 from https://www.nmth.gov.tw/en/content_45.html.

della Porta, Donatella (2014) Mobilizing for Democracy: Comparing 1989 and 2011, Oxford: Oxford University Press. 
Sandell, Richard (1998) 'Museums as agents of social inclusion', Museum Management and Curatorship 17(4): 401-418.

Shih, Shu-mei; Harrison, Mark; Chiu, Keui-fen; and Berry, Michael (2018) 'Position paper: Linking Taiwan studies with the world', International Journal of Taiwan Studies 1(1): 209-227.

Sullivan, Jonathan (2011) 'Is Taiwan studies in decline', The China Quarterly 207: 706-718.

Swarthmore College (no date) 'Taiwanese student sit-in for democratic reform (Wild Lily Movement) 1990', Global Nonviolent Action Database. Retrieved 10 February 2020 from https://nvdatabase.swarthmore.edu/content/taiwanese-student-sit -democratic-reform-wild-lily-movement-1990.

Tarrow, Sidney (1994) Power in Movement: Social Movements, Collective Action and Politics, Cambridge: Cambridge University Press.

Williams, Mary Elizabeth (2017) 'A noble balancing act: Museums, political activism and protest art', Museum International 69(3-4): 66-76.

Wright, Teresa (1999) 'Student mobilization in Taiwan: Civil society and its discontents', Asian Survey 39(6): 986-1008. 